\title{
Baltic States and the Euro: A Spectral Analysis of the 2007 Financial Crisis
}

\section{Introduction}

The robustness of a fixed exchange rate system is a function of credibility (de Grauwe 2003). Credibility emerges when the commitment to maintaining a fixed exchange rate is demonstrated tangibly. The Baltic States have initiated policies aimed at acceding to the European single currency or 'Euroizing'. Under convergence criteria, to Euroize legally governments should peg their exchange rates with the Euro within a system known as ERMII for at least two years and fulfil other conditions. The convergence period leaves these small economies exposed for a window of time that may or may not be benign. Van Poeck et al. (2007) find that membership of the ERMII can increase the vulnerability to a speculative attack. By contrast, De Grauwe and Grimaldi (2002) and De Grauwe (2003) argue that because of self-imposed costs of reneging on the commitment to ERMII membership, the likelihood of an exchange rate crisis is lower. The impact and transmission of a crisis may vary with the type of regime. Fischer (2001) posits that 'soft' peg exchange rates are not sustainable. Would a crisis undermine convergence?

The Bank of England (2008) marks $9^{\text {th }}$ August 2007, when BNP Paribus suspended three sub-prime money market funds and the European Central Bank injecting $€ 95$ bn to boost liquidity in the European banking sector, as the beginnings of the banking turbulence. The analysis undertaken here focuses on the exchange rates of the Baltic States and the Euro. Specifically, although they resisted, were these ERMII currencies put under more pressure to devalue as a result of the banking crisis that began in August 2007? It is hypothesised that the Baltic States would be subject to 
adverse speculation in a non-benign era whilst in the window of convergence, putting pressure on the pegged rates, leading to greater divergence from central rates. The paper covers the year before (the benign period), and the year after (the contagious period). This year captures the banking crisis that became evident in the US and Western Europe in 2007 (the event) but concludes before the Lehman Bros. collapse, so covering a 'small shock' period.

The paper is compiled as follows. In the second section, there is a discussion of currency arrangements in the Baltic States. This is followed by a review contagion and literature concerning financial contagion over numerous crises. Next, there is an outline of the background or setting of the study. The subsequent sections review the data and the methods. The results reveal that, unexpectedly, the currencies appear to follow the Euro at least as closely and perhaps more so, following the event. It is concluded that there is contagion between the Euro and the three currencies. This contagion appears favourable for a fixed currency regime and this is unaffected by the type of regime. However, phase spectra support a view that banking links, which are not affected by the currency regime, may have transmitted a crisis to the Baltic States.

\section{Baltic States}

The IMF (2004) classifies the range of fixed exchange rate alternatives. To maintain a credible fixed exchange rate, the central bank would accommodate the excess demand or excess supply of its currency by intervening in the foreign exchange or money markets to neutralise, as it were, the excess. Some latitude is exercised in the immediacy of the response and the degree of neutralisation. With ERMII membership Lithuanian and Estonian currencies were required to be within a $\pm 15 \%$ band with the Euro. Lithuania and Estonia operate a currency board system, which results in a 
degree of latitude of practically zero. Although it aims to have sufficient reserves to cover domestic money, Latvia operates an 'Other Conventional Fixed Peg Arrangement'. Here, although there is not the same commitment to keep the parity irrevocably, there is a concerted effort to maintain the within narrow margins of less than $\pm 1 \%$ around the central rate.

Joseph-Khoury and Wihlborg (2006) suggest that, in effect, by forming a currency board, Estonia has outsourced monetary policy. Moreover, the scale of dependence of domestic retail banking on Swedish banks is made evident in Table 1.1 of the IMF's Global Financial Stability Report (2009). By permitting the takeover of so much of its domestic banks, it also outsourced its lender of last resort function to foreign authorities. The outsourcing of both bred confidence in the banking system and the money. Estonia, Lithuania and Latvia have similar banking structures.

Over the period 2006-2008, the Baltic States faced significant problems. Price and wage inflation and interest rates were beyond the acceptable thresholds of the convergence criteria. Through lax lending by Scandinavian banks, a credit growth rate of an average annual rate of at least $27 \%$ (IMF, 2009) resulted in property price bubbles that burst at the end of the period studied. For example, the Latvian house price-net earnings ratio peaked in the second quarter of 2007 and average rents peaked in August 2007 (Latvijas Banka, 2009). Latvia appeared to be in a worse position than the other two in the way the economy was overheating.

\section{Contagion}

Modern portfolio theory advocates that investors should manage risk through diversification across a variety of assets (Cuthbertson, 1996). Dispersing investments 
across two assets that are not perfectly correlated should reduce risk exposure. Diversification in asset types is based on the view that each is a function of a distinctive group of variables (Hoesli et al., 1997). If a shock has a contagious impact, the markets behave more similarly after the shock, which implies that contagion captures a change in the data generating processes: it suggests that the forces behind the price movements are less distinct as a result of the shock. Thus, contagion undermines the basis of portfolio management.

Pericoli and Sbracia (2003) present six definitions of contagions; the fifth, (shift) contagion, is relevant for the approach taken here. Shift contagion entails a change in the transmission of financial activity between markets. The change can include intensification as well as structural change in the rate or timing of flows or interactions. Commonly, the term contagion is associated with the relationships between portfolio assets being intensified. By contrast, intensification could herald greater market integration, so strengthening regional economic associations. Thus, intensification could be a favourable or an unfavourable change.

\section{Literature Review}

Central European economic indicators have been examined for contagion, some with adopting the inception of the European single currency as a marker. Using stock market indices of Czech Republic, Slovakia, Hungary and Poland, the S\&P500 and the Dax, pre- and post-EMU creation, Syriopoulos (2007) finds that the emerging markets appear to be no more strongly linked to those of the US and Germany. He finds one cointegrating vector in both periods suggesting that there is no strengthening of links in the long run. Using residuals from error correction models in a correlation 
test, Yang et al. (2003) find that EMU led to greater integration of larger stock markets across Europe that adopted the Euro. Innovation accounting indicates that smaller and non-Eurozone (UK's) stock exchanges appear less well integrated. No clear pattern emerges of integration or disintegration between the US stock market and the other eleven considered. Examining the same phenomenon as Yang et al. but using a GARCH-M model, Westermann (2004) finds that, following EMU, daily lead-lag relations between France, Germany and Italy disappeared, but the US market still played a significant leading role. The latter two proffer similar conclusions: EMU precipitated greater market integration.

In their study of Central European stock markets, Serwa and Bohl (2005) find that Central European stock markets are no more likely to be subject to contagion than western stock markets over the 1997-2002 period and that the Central European stock markets exhibit interdependence rather than contagion.

Using a bivariate cointegration approach, Maneschiöld (2006) finds that the Baltic States' stock markets are integrated with those of the Germany, France and the UK over the period 1996-2005. Interestingly, the Baltic States themselves are not integrated in the long run. There are short run links from European and US markets to the three states but not the converse. From a portfolio diversification perspective, Maneschiöld advocates seeking longer, rather than shorter-term benefits.

In an examination of the British term structure of interest rates, Hughes-Hallett and Richter (2004) use spectral analysis. Estimating gain and phase spectra of British 10 and 2 year bond yields for before the episode, they compared the 'profiles' or patterns of the spectra with those during and after the ERM crisis of 1992/3. Gain is akin to a regression coefficient and a phase value, like a lag, reveals a delay, but they are estimated for each frequency. The initial consequences of the crisis are revealed 
by portions of the profiles falling outside the confidence band from the pre-crisis coefficients at lower frequencies. Gain altered notably over the first two months but reverts to the pre-crisis pattern by 1998. The phase change entails smaller delays. In the initial period, delays between long and short-term interest rates at the longer cycles vary between a fraction of a day to over a week. Following the ERM ejection, the profile becomes flatter but remains inside the lower bound. However, from 1993 the profile at the low end falls outside the confidence interval of the pre-shock band and becomes flat, i.e. no-delay turns out to be persistent. This is symptomatic of a structural change, consistent with contagion. They conclude that Sterling's ejection from the ERM resulted in changes in risk premia or liquidity preference. Underlying relationships, which determine the effectiveness of monetary policy, as revealed by gain, were relatively stable.

Levy and Dezhbakhsh (2003) explore output fluctuations and shock persistence using spectral and other methods. They examine growth rates of real GDP spectra of 53 countries. Normalising the spectral estimates and creating output variations associated with short, business and long cycles, they consider peaks in the spectrum relative to the long run value (i.e. at zero frequency). Using the lower bound of the former relative to the upper bound of the latter, they reveal significant peaks in the spectrum that are used to classify nations.

A most unusual approach due to Smith (2001) and reviewed by Wang (2003b) entails a cross-spectral analysis of the impact of the 1987 crash on equity markets of the Pacific Rim. Using coherence among pairs of asset markets for portfolio construction purposes, Smith reveals intensification through increased coherence. He seeks to reveal changes in the relationships amongst five markets across North America and South East Asia for portfolio diversification proposes. Cross-spectra are 
estimated over a set of frequencies, not just one, so finding heightened coherence at one frequency may be coloured by conflicting evidence at another. He uses Wilcoxon's Z-statistic to assess whether the two spectra of coherence are drawn from the same population.

The Australia and US phase spectrum has generally a positive linear trajectory with extreme values of zero and $\pi$, suggesting a delay of one period (day) of the former behind the latter, which could reflects time zones. Wang (2003a) points out that the time domain analysis of common cycles could not accommodate the complexity of cycles that are not in a similar phase at higher frequencies.

Asimakopoulos et al. (2000) investigate leads/lags and integration among equity markets. The US market exhibits high coherence with European ones at low, but not high frequencies. Also, they find 11 to 13 day cycles in the spectral densities of all four indices.

\section{Methodology: Spectral Analysis}

Spectral and cross-spectral analysis can be seen as means of revealing variance and co-variance, but in the frequency domain. As no prior model is assumed, Kendall and Ord (1990) view the approach as non-parametric. If the power spectrum is large at frequency $\omega_{j}$, it indicates that variable $X$ has a concentration of variance at that periodicy. The equivalent of the coefficient of determination in cross-spectral analysis is coherence (squared coherency). If the coherence is large at frequency $\omega_{j}$, it indicates that variables $X$ and $Y$ have a concentration of co-variation at that periodicy. Displayed in figures 2 to 4 are three pairs of power spectra one for the pre and one for the post-event eras. Although the Litas forms part of the analysis, its profile tends to 
duplicate that of the Kroon, so for brevity's sake will not be reporduced. Each of the Baltic currencies is paired with the Euro to produce cross spectra. In each case, the exercise is repeated, once using pre- currency data and one post-shock era. There is then a consideration of whether the two cross-spectra are drawn from the same sample. This corresponds to a null of no change against an alternative of contagion (weaker or stronger links). When considering this null, Smith (2001) uses Wilcoxon's Z-statistic. Conover (1971) states that the distributions should be symmetrical. If not, the less powerful Sign test can be used.

The phase value presents a notion of lead-time (if positive) of the first series $X$ over the second $Y$ at (angular) frequency $\omega_{j}$. The confidence interval for a phase value is determined by the corresponding level of coherence. The phase values are converted into the time domain measures (known as tau $=\tau$ ), so that any lead or lag is displayed in fractions of a day.

Pericoli and Sbracia's (2003) 'shift contagion' focuses on changes in structure. Structural change can include transformations in the configuration of delays or speed of adjustment as well as a strengthening of links. An acceleration of the transmission mechanism, reducing the delay between impulse and reaction, implies a structural change in asset markets interaction. Faster shock transfer is posited to be reflected in smaller values/fewer significant values of tau or a greater weight of emphasis on the higher frequencies. Pericoli and Sbracia also ask over which frequency should a crisis in one country trigger turbulence for another? It is possibly that there is a significant lag. It is far from obvious that changes should lead to higher correlation at daily weekly or monthly cycles. Indeed, they may lead to a lowering of correlation over some of these frequencies. 


\subsection{A Well Functioning Fixed Exchange Rate}

Using a non-Euro common base, such as the Dollar, comparisons are made directly between the Kroon, Lat and Litas. If the fixed exchange rate is working effectively, there should be no difference between the long run dynamics of the Euro and the currencies of the Baltic States. There will be some delay between movements in one currency and adjustments in another, which should be more evident in the short run.

A currency crisis does not always emerge from a financial crisis (Kaminsky et al., 2003; Pericoli and Sbracia, 2003). In a pegged exchange rate sense, financial contagion, as a notion of dislocated relations, would be reflected in a greater dissimilarity of movement and longer deviations from central rate, associated with intense pressure on the central bank to maintain parity. One would anticipate the shock could provoke a lower level of confluence among a pair of currencies as measured against a third. The arbitrage process would appear more imperfect.

Given Van Poeck et al. (2007) assertion that membership of the ERMII can increase the vulnerability to a speculative attack, the Baltic States' currencies should, following a shock:

1. exhibit a notable change (fall) in the co-movement with the Euro;

2. exhibit a disruption to money flow patterns; and

3. as the Latvian currency operates in less hard peg regime, it should exhibit lower co-movements and more disruption than the other two currencies against the Euro, particularly after the shock.

Exchange rates are commonly seen as following a random walk (Cuaresma and Hlouskova, 2005). Reflecting a perfectly maintained peg, coherence, one would anticipate, at low frequencies, would be close to 1 . At high frequencies, reflecting 
turbulence and arbitrage or central bank intervention, coherence would be lower than found at the lower frequencies.

Non-zero tau, if not indicating a delay across the spectrum may, it is proposed, reflects spot market foreign exchange periodicies, such as money market contract periods. Consequently, leads in currency movements should reflect capital flows from one market to another for short-term investment or possibly speculative purposes, which, with a delay, are subsequently sterilised by compensating changes in central bank reserves or other currency movements by multinational banks.

\section{Data}

Data for the Estonian Kroon, Latvian Lat and the Lithuanian Litas and the Euro, all measured in US Dollars, are taken from the Bank of England's statistics website for the period 9806 to 8808 . This covers 507 daily foreign exchange spot rates $(F X$ rate), with the shock or event occurring at the mid point on the $9^{\text {th }}$ August 07. Plots of the logged series over two years are displayed in Figure 1. Using two scales to reflect the different nominal values, there may be a (significant) slow drift downwards in the levels of the data. It appears as if there is notably more variation in the right-hand scaled currencies. This is misleading: they are tightly bound together, reflecting the ERMII peg. 


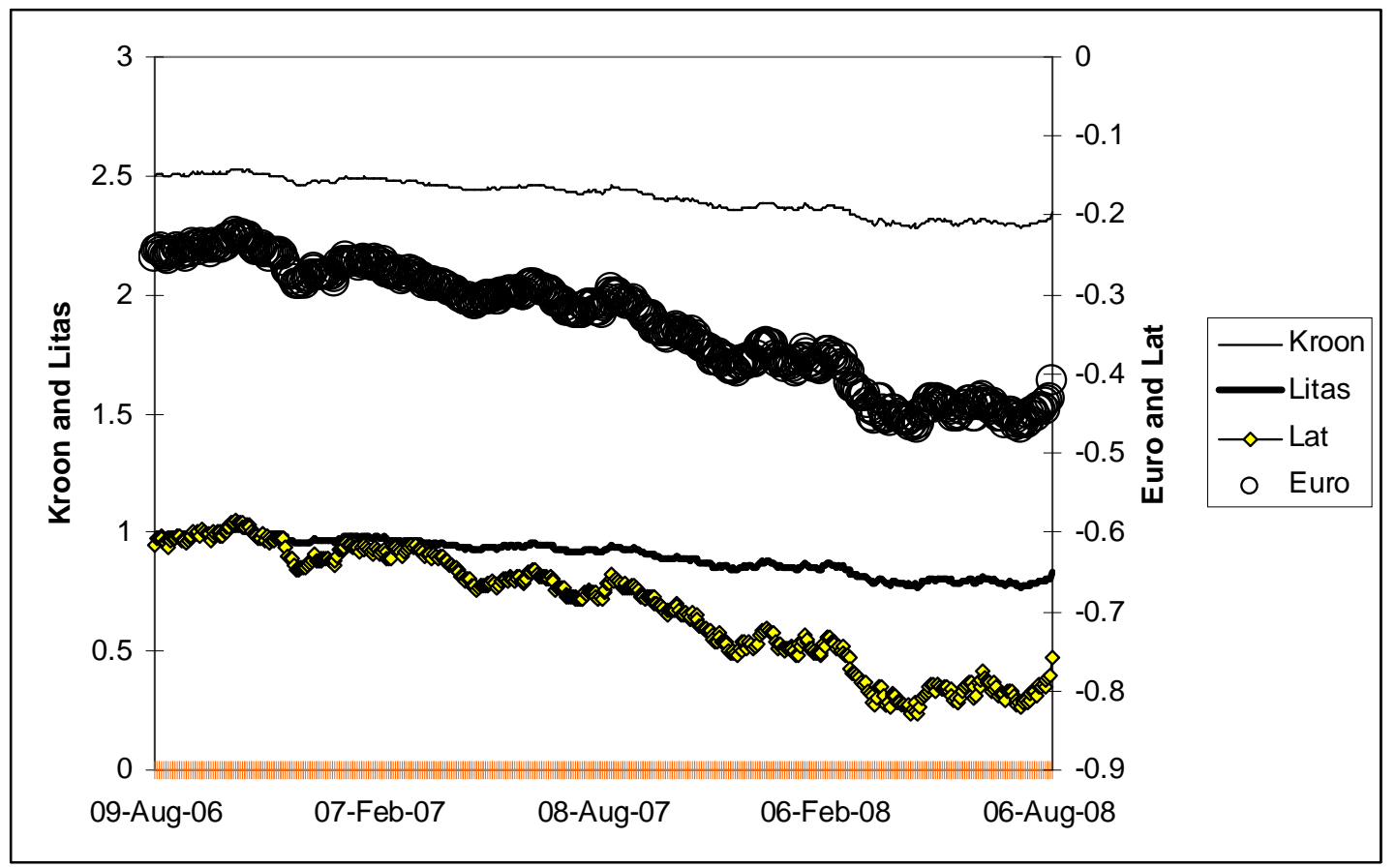

Figure 1. Logged Exchange Rates against the US Dollar.

Despite being measured in Dollars, the Euro/Kroon and the Euro/Litas follow a linear relationship. In other words, any adjustments between the currencies occur so quickly that the fixed exchange rate is maintained almost always within a day. The Euro/Lat relation is not so tight.

\subsection{Structural Break}

One can utilise Chow tests to consider the hypothesis of a structural break. There are two variants that are commonly used. The coefficient stability test, the Chow test I, reveals whether the parameters estimated over the benign period continue are appropriate over the crisis period. Chow test II or the predictive failure test assesses whether the estimated parameters in the benign and crisis periods are significantly different from each other. Violation of either the coefficient stability or predictive 
failure test may be interpreted as evidence of a structural break in the data. The tests are predicated on homoscedastic errors. In (1) there is a AR(2) model of the (logged) Euro time series in the benign period with $t$ - ratios in brackets.

$$
\begin{aligned}
\text { LEuro }_{t}= & -.0017418+.97122 \text { LEuro }_{t-1}+.023388 \text { LEuro }_{t-2} \\
& (-.76612)(15.2292)
\end{aligned}
$$

$\underline{\text { Diagnostic tests }}$

\section{Serial Correlation} ARCH (OLS) Predictive Failure Normality

$\begin{array}{lrlr}\text { CHSQ }(1)=.52755[.468] & & \text { Functional Form } \\ \text { CHSQ }(2)=.56159[.755] & \text { Heteroscedasticity } \\ \text { CHSQ }(253)=617.0179[.000]^{*} & \text { Chow Test I } \\ \text { CHSQ }(2)=.79371[.672] & \end{array}$

$\bar{R}^{2}=.983$

$\operatorname{CHSQ}(1)=.52755[.468]$

$\operatorname{CHSQ}(1)=2.0280[.154]$ $\operatorname{CHSQ}(3)=3.8986[.273]$

The diagnostic tests suggest that the model is well specified and the coefficients indicate that the model could be re-expressed as a difference stationary variable: consistent with the efficient market hypothesis, as a random walk. Predictive Failure test indicates that there is at least one structural break over the two-year period.

Following the above, the (logged) data from the four $F X$ rate series are considered for unit root. ${ }^{1}$ From these, it is concluded that the data is difference stationary.

As displayed in Table 1, the standard deviation for each logged differenced series is greater after August $9^{\text {th }} 2007$ compared with before, which is consistent with the presumption that a crisis causes turbulence. This is confirmed by Levene's homogeneity of variance test. The table also shows that, using a KolmogorovSmirnov test, there is no sub-sample where there is significant deviance from the null of normality. Coefficients of skewness and kurtosis for the Kroon and Litas are indistinguishable. The skewness of the Lat is higher than those of the others, but not

\footnotetext{
1 The test for unit root entailed the Perron (1989) modified Augmented Dickey-Fuller (ADF) expression, $\Delta x_{t}=\alpha_{0}+\alpha_{1} D+(\rho-1) x_{t-1}+\beta_{0} t+\beta_{1} D t+\sum_{j=1}^{p} \gamma_{j} \Delta x_{t-j}+\varepsilon_{t} \varepsilon_{t} \sim \operatorname{iid}\left(0, \sigma_{\varepsilon}^{2}\right)$ where $p$ is the order of the lag polynomial set to one. $D$, the dummy, takes a value of 0 before and 1 after the crisis began. If the coefficients on $D$ are zero, the expression reverts to the ADF test.
} 
significantly so. Kurtosis is positive and significant before the event but not after. Generally, the coefficients in Table 1 suggest the Kroon and Litas are indistinguishable from the Euro, whereas the Lat has slightly differences.

The row labelled Standard Deviation shows that the turbulence suffered by the three currencies is very similar to that of the Euro. Using an $F$-test, there are no statistical differences between any pairs. The ones where the contrasts are likely to be the most pronounced (Euro-Lat) are not significant (pre-event $[p=0.276]$, post-event $[p=0.388])$. The Chow tests are predicated on common variance. It could be that, as posited with a crisis but with a fixed exchange rate, the structural change concerns volatility.

Table 1: Exchange Rate Descriptives

\begin{tabular}{|c|c|c|c|c|c|c|c|c|}
\hline & \multicolumn{2}{|c|}{ Estonian Kroon } & \multicolumn{2}{|c|}{ Lithuanian Litas } & \multicolumn{2}{|c|}{ Latvia Lat } & \multicolumn{2}{|c|}{ Euro } \\
\hline & Before & After & Before & After & Before & After & Before & After \\
\hline Normality ( $p$-value) & .419 & .248 & .415 & .243 & .479 & .338 & .412 & .310 \\
\hline Standard Deviation & .0035287 & .0054296 & .0035284 & .0054333 & .0036640 & .0055315 & .0035292 & .0054335 \\
\hline Levene test ( $p$-value) & \multicolumn{2}{|c|}{.000} & \multicolumn{2}{|c|}{.000} & \multicolumn{2}{|c|}{.000} & \multicolumn{2}{|c|}{.000} \\
\hline Skewness $(\mathrm{se}=.153)$ & .042 & .265 & .041 & .266 & .206 & .242 & .048 & .263 \\
\hline Kurtosis $(\mathrm{se}=.305)$ & .253 & .317 & .250 & .319 & .698 & .195 & .259 & .308 \\
\hline
\end{tabular}

\subsection{Power Spectra}

As comparisons of spectra are based on particular frequencies, there is a problem with synchronising dates. National holidays and leap years can disrupt the synchronicity. To address this, the Bank of England data is extended so that there is an exchange rate value for every weekday, whether it is a working day or not. This is achieved by using the most recent rate in the levels of the data before the non-trading weekday. The two sets of 256 days are taken from Thursday $9^{\text {th }}$ August 07 and the equivalent Thursday in 2006.

For the power spectra, coherence and phase, corresponding to 256 to 2 periods (days), coefficients for 128 (angular) frequencies $(f)$, will be estimated. These range 
from 0.00390625 to 0.5 radians (a radian $\omega_{j}=2 \pi f_{j}$ ). In addition, there is the long run coefficient at zero frequency. The general pattern for all four power spectra in Figures 2-4 is that, at all frequencies, the post-event values are above the corresponding ones for before. As well as the spectra, confidence intervals are displayed. One question to address is whether the changes are significant. Hughes-Hallett and Richter (2004) and Levy and Dezhbakhsh (2003), in combination, proffer two alternatives methods to address this. One could consider whether the values of the spectrum after the event fall outside the confidence interval for the upper confidence interval boundary of the spectrum values before the event. Alternatively, one could examine whether the lower band of the after-event spectrum is above the upper bound of the before-event spectrum. The latter is a more onerous test to pass. When using the confidence intervals (con. int), outside of a few cases around 6 and 21/2-day cycles, the after-event profile is greater than before. This upward shift reflects greater volatility in exchange rates across the spectrum.

If attention is shifted to the variance at each frequency for the Euro, both preand post-event have a peak around 0.1 radians. For the pre-event profile, it is at a cycle of 7.8 days, whereas the after-event profile, it is 9.5 days, i.e. 2 weeks. After about 0.17 radians there appears to be a notable change in the profiles. Between this point and around 0.4 radians, there is an inverted U-shape in the post and a flat or even a U-shape in the pre-event profile. After 0.4 radians there again appears to be a mirroring of the profiles. In other words, following the event, the volatility associated with exchange rates shifted between cycles. In particular, there is a greater concentration in certain bands. It is notable how higher frequencies are more strongly featured. This can be interpreted as a shift towards shorter-term trading, including speculation. Hughes-Hallett and Richter (2004) find that, following the ERM crisis, 
there is also a shift towards the higher frequencies in the gain spectrum. In a period of information paucity, traders shifting to a shorter-term horizon may be appropriate.

There are 37 power spectrum values before, and 25 after, the start of the crisis that fall outside the confidence interval for the long run coefficient, all but two are below the lower bounds. This suggests that there is some variation in the distribution of the variance across the cycles and it is not white noise.

By eye, the profiles of the four countries' exchange rate power spectra are similar both before and after the event. Although not a recognised measure, a Spearman's rank correlation of the Euro power spectrum before the event with those of Latvia, Lithuania and Estonia produce values of $0.8,0.998$ and 0.999 . The corresponding figures are $0.92,0.99$ and 1 for the post-event era. In other words, despite greater volatility, the event led to more similar profiles. These figures should correspond to very high coherence coefficients, with increasing values after the event. The pre- and post-event spectra for the Euro are correlated, but negatively $(-0.42)$ which implies a structural change.

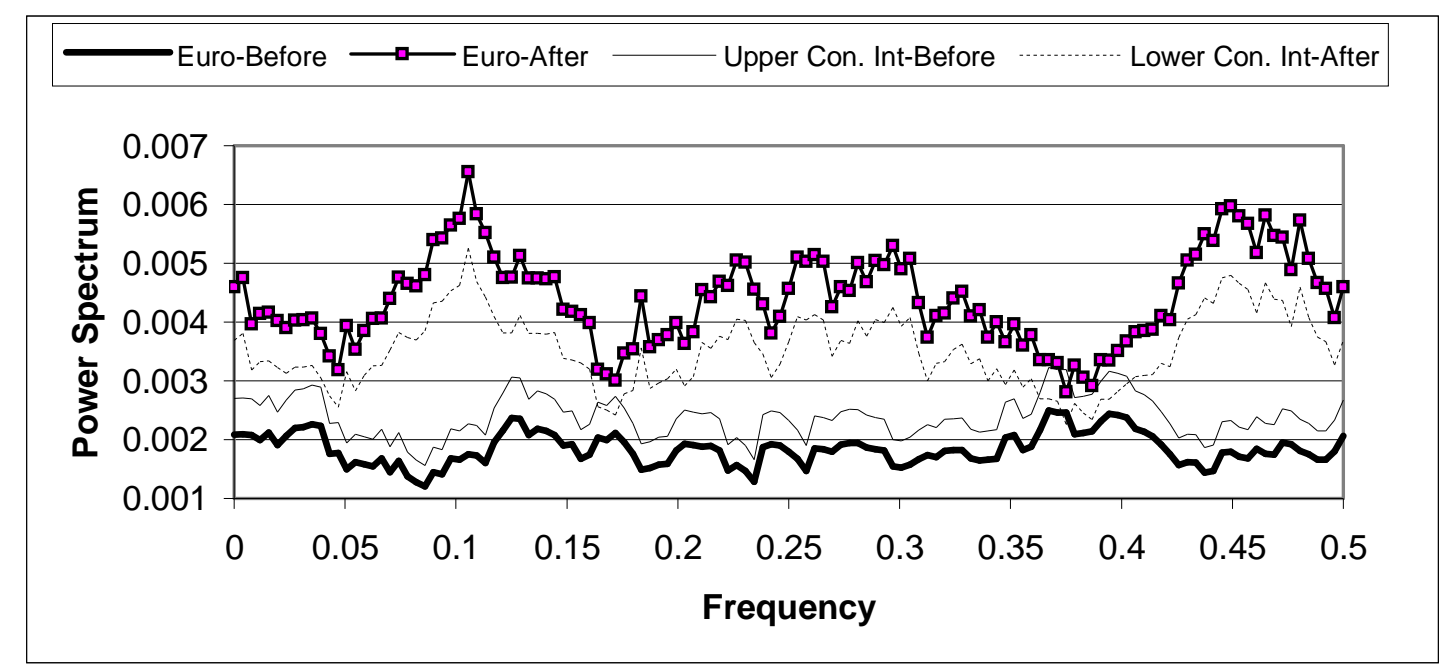

Figure 2. Power Spectrum - Euro Before and After the Event, with Confidence Intervals 


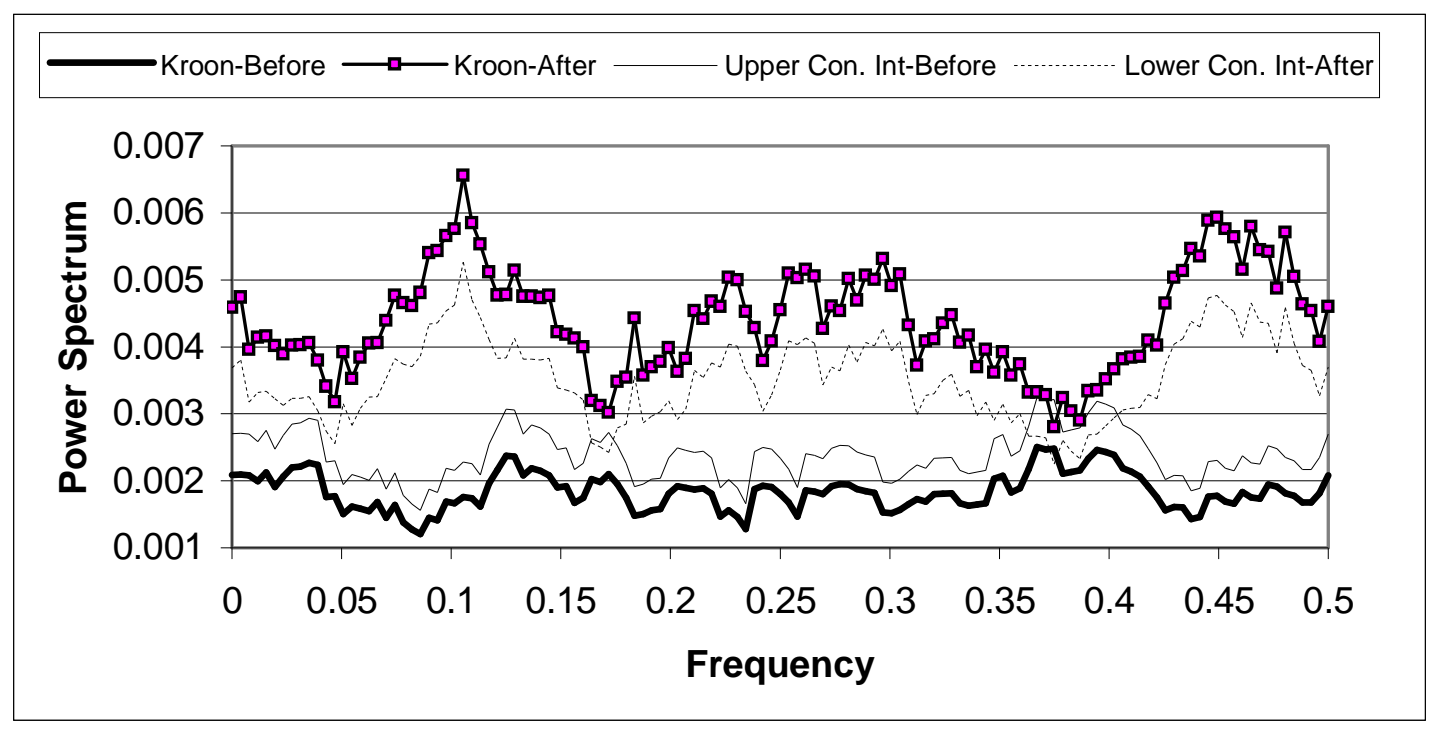

Figure 3. Power Spectrum - Estonian Kroon Before and After the Event, with Confidence Intervals

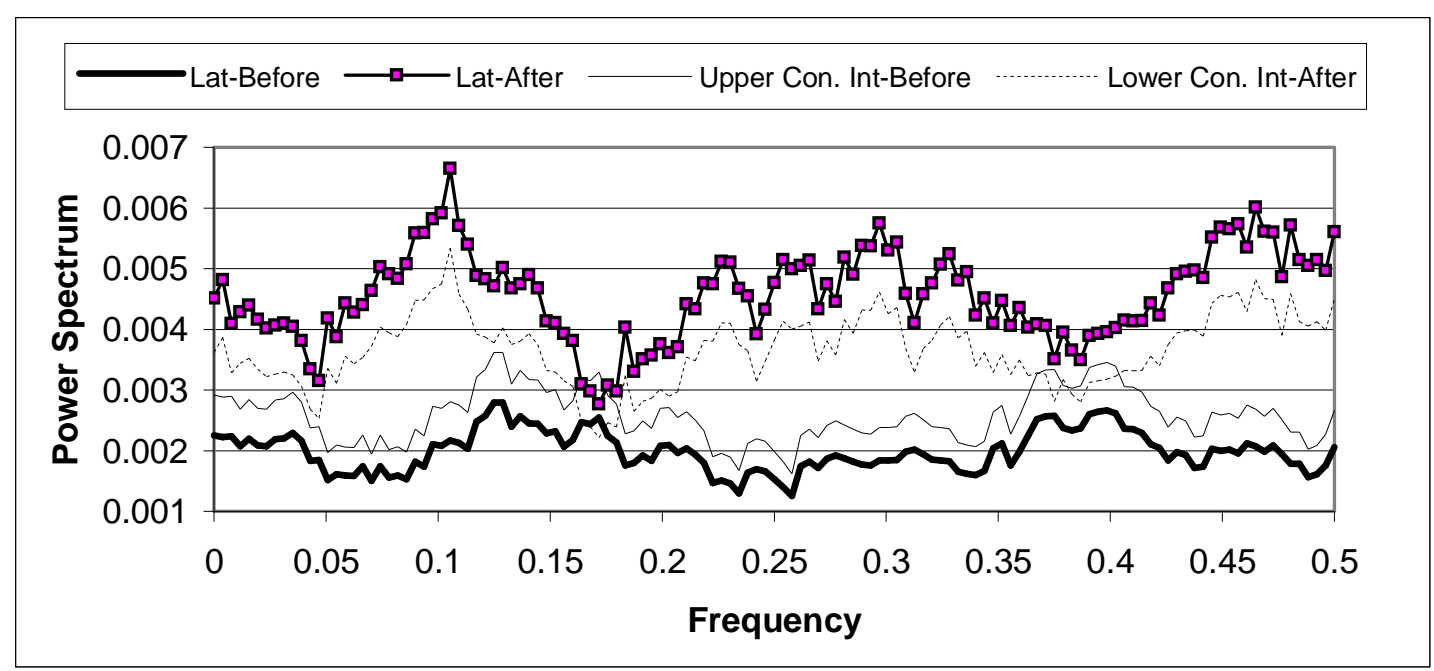

Figure 4. Power Spectrum - Latvian Lat Before and After the Event, with Confidence Intervals

\section{Cross Spectral Results}

Figures 5 and 6 display coherence spectra. They suggest higher coherence levels 
following the event in the higher frequencies. Both the Kroon and the Litas are currency board-controlled exchange rates with a 'zero' fluctuation. There is a clear divide between the Lat, in Figure 6, and the other two: the coherence values of the Lat are lower than those of the Kroon and Litas. The Lat fluctuates within a $2 \%$ band, which, if utilised, explains the lower level of coherence. Most importantly, the postevent coherence profile appears above the pre-event, indicating a closer shadowing of the Euro after the event.

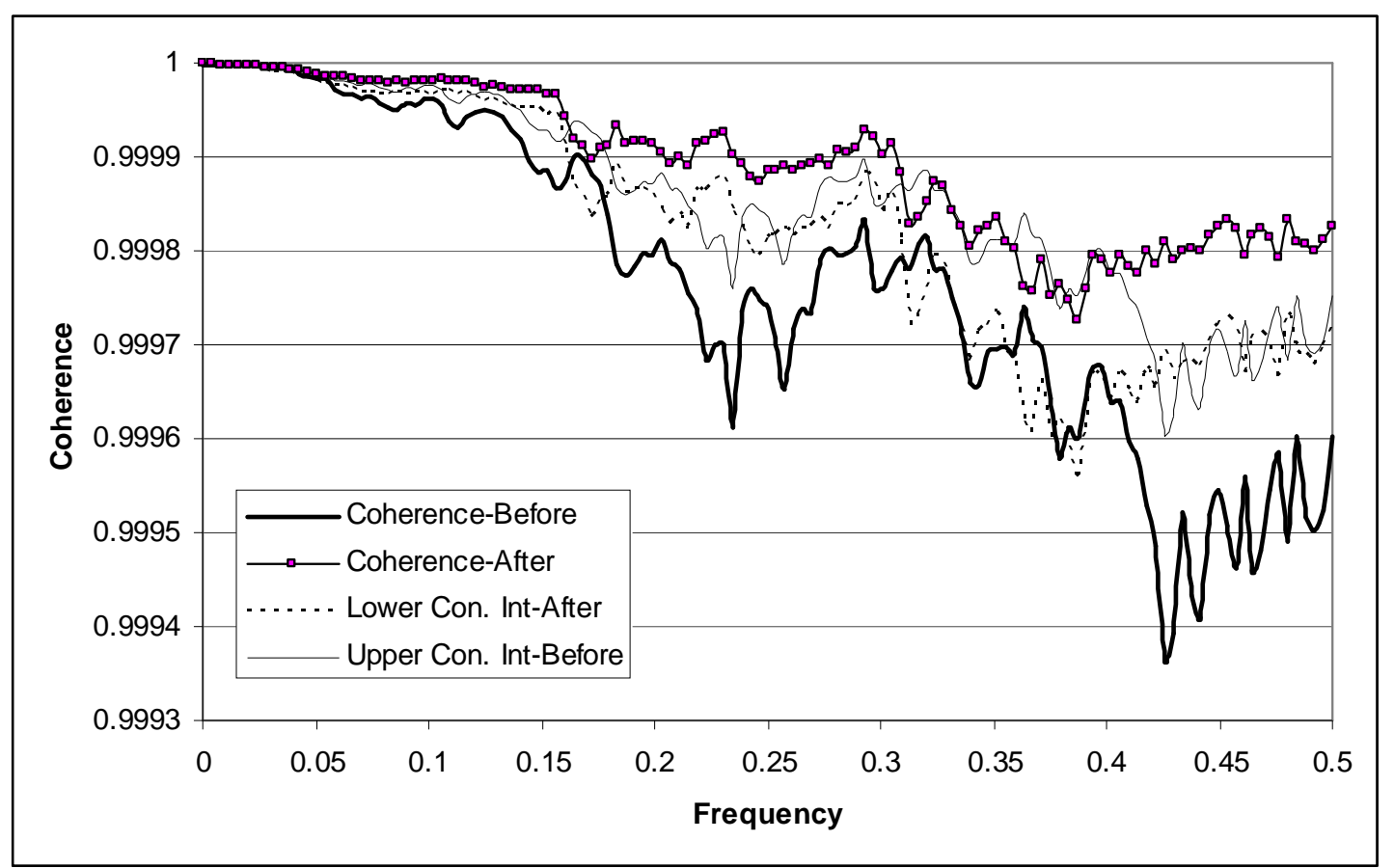

Figure 5. Coherence - Euro/Kroon Before and After the Event, with Confidence Intervals 


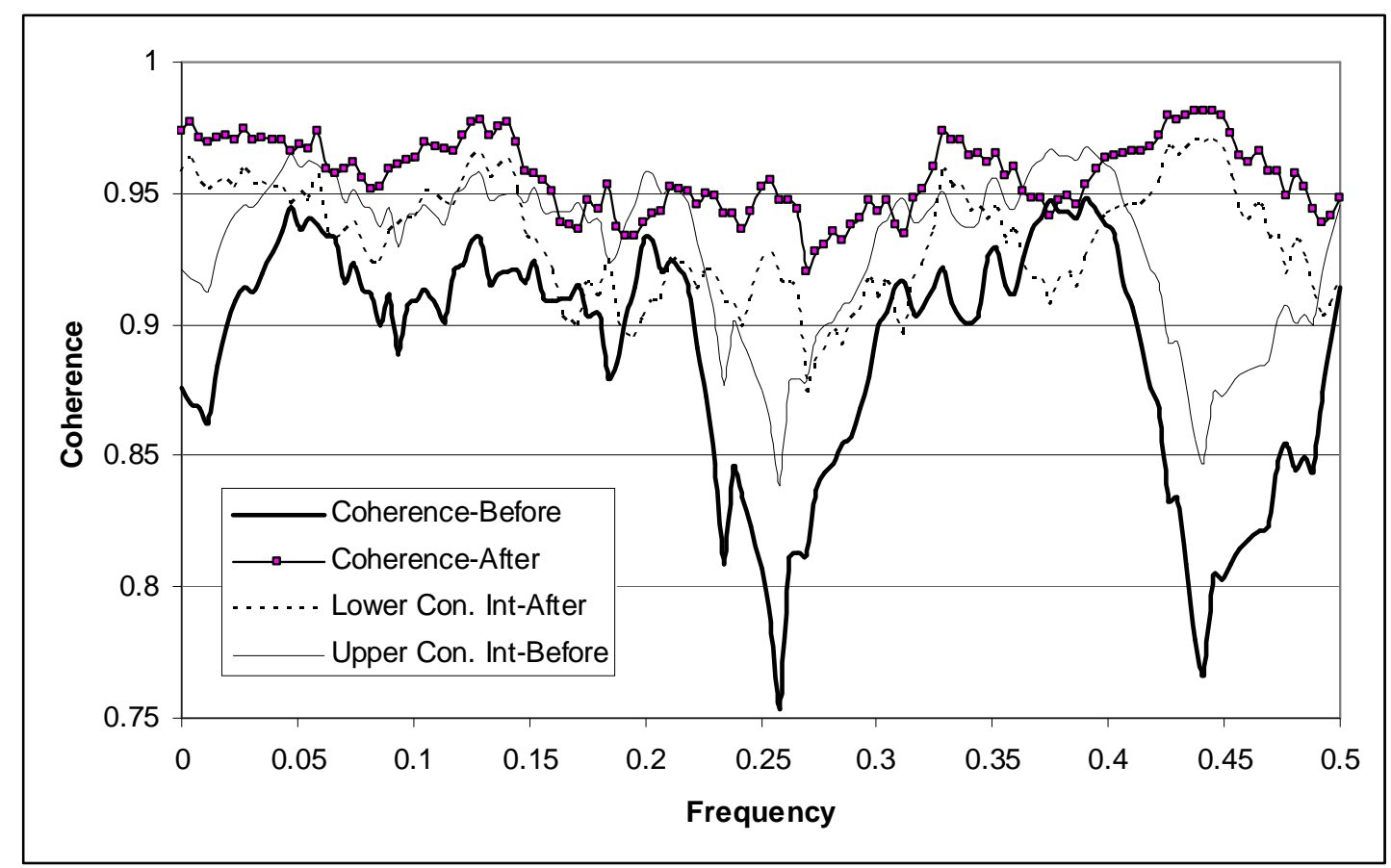

Figure 6. Coherence - Euro/Lat Before and After the Event, with Confidence Intervals

Using confidence intervals in a similar manner to the power spectra, in the case of Latvia, there are 59 (110) frequencies where the after-event coherence confidence interval is above the upper interval for the pre-event coherence. With Lithuania and Estonia, the corresponding numbers are 10/63 and 31/97. These suggest an increase in coherence for Latvia but the evidence for Lithuania and Estonia is not as supportive.

The mean, median, standard deviation and maximum value are reported in Table 2. Examining the coherence levels of the 129 frequencies, the means and medians exhibit the same direction of change. The mean coherence value of 0.889 for the Euro and the Lat pairing before the event rose to 0.958 in Table 2. The median value rose by a similar margin from 0.901 to 0.958 . The coherence values after the event are distributed normally $([p=.283])$ but not before $([p=.002]$ respectively). The Wilcoxon Z-statistic is predicated on a symmetric distribution, so a test of skew is included. It revealed that the distribution of coherence values is not symmetrical. As such, rather than using a Wilcoxon test, a Sign test is appropriate. As it turns out, the 
results are not distinguishable. From observing the pattern of coherence for all three pairs, the null of being drawn from a common pool is rejected $[p<.000]$ : coherence is greater after the event for all three pairings. Rather than declining, the Baltic States' currencies mirror the Euro more closely. These results are less ambiguous than the considerations using confidence intervals, and they are in accord with analyses using the power spectra.

Table 2. Descriptive Statistics and Sign and Wilcoxon Test for Coherence

\begin{tabular}{|c|c|c|c|c|c|c|c|c|}
\hline & Mean & $\begin{array}{c}\text { Std. } \\
\text { Deviation }\end{array}$ & Median & Max & Normality & $\begin{array}{c}\text { Skew } \\
(\mathrm{se}=.213)\end{array}$ & Wilcoxon & Sign \\
\hline Euro/Lat-a & .956948 & .013949 & .9580 & .981625 & .403 & -.187 & \multirow{2}{*}{.000} & \multirow{2}{*}{.000} \\
\hline Euro/Lat-b & .889334 & .045070 & .9073 & .948389 & .000 & -.968 & & \\
\hline Euro/Litas-a & .999842 & .000105 & .9998 & .999997 & .012 & .033 & \multirow{2}{*}{.000} & \multirow{2}{*}{.000} \\
\hline Euro/Litas-b & .999714 & .000227 & .9997 & .999995 & .096 & -.753 & & \\
\hline Euro/Estonia-a & .999892 & .000078 & 9999 & .999999 & .012 & -.180 & \multirow{2}{*}{.000} & \multirow{2}{*}{.000} \\
\hline Euro/Estonia-b & .999769 & .000169 & .9998 & 999998 & .096 & -.355 & & \\
\hline
\end{tabular}

Rather than the hypothesised lower values suggestive of pressure on the maintenance of the peg, the coherence evidence appears to support De Grauwe and Grimaldi's argument that the likelihood of an exchange rate crisis is lower because of the selfimposed costs of reneging on the ERMII commitment. Depending on the method, all three ERMII members exhibit either no or an increase of coherence, which is favourable intensification. Given the high values, the confidence interval approach may not show a clear change. However, with Latvia, there is a stronger case for concluding an increase in coherence. This country, with 'worse' characteristics and a 'softer' peg, appears not to have been precluded from this shift, which does not sustain Fischer's concerns. 


\subsection{Phase Spectra}

For a given phase, $P_{X Y}\left(\omega_{j}\right)$, a corresponding time shift in the time domain is tau $(\tau)$. Rather than presenting the phase value, tau is displayed, so the scaling on the ordinate is in units of time. The symbol ' + ' indicates a tau value before the event and '-' signifies tau after the event at a particular frequency that is significantly different from zero at the $5 \%$ level. The two symbols should be laid on one another where there is no [structural] change.

There are significant frequency groups for both pre- and post-event periods where similar leads and lags are evident. Periodicies that could reflect money market contract term, such as two months, one month, two weeks and a week emerge. As these are short and standard periods that do not indicate a delay across the spectrum, they could reflect timings and directions of money flows. For example, after the event, the Euro leads the Litas by one minute at $0.35,0.2$ and 0.1 radians (just under 3 days, a week and two weeks) but the Euro lags the Litas by 2 to 3 minutes at less than 0.05 radians (a month). With all three, there are frequency groups where the Euro leads and then lags the Baltic currencies. This could be interpreted as money movements from, for example, Lithuania to Europe on a shorter-term basis than it flows the other way.

Another dimension of contagion is captured by the phase value. HughesHallett and Richter (2004) did not make much of the change in the phase spectra other than to point out that, following the crisis, it became flatter persistently. Phase for the Euro/Kroon (in Figure 7) and Euro/Litas present similar profiles. Rather than perfect alignment, they show up to 3-minute delays in exchange rate variations. This suggests some currency-sensitive, possibly automated, processes are in place to sterilise discordant currency flows. By contrast, phase for the Euro/Lat in Figure 8 suggests 
the adjustment takes place within 2 hours; quicker at higher frequencies in both the pre and post periods. The slower adjustment is in keeping with the lower coherence and use of a broader, $2 \%$ band.

The event led to money markets drying-up in London, raising short-term interest rates to very high levels, precipitating the collapse of Northern Rock in the UK and central banks became, for a time, the lenders of only resort. The Kroon and Litas have similar lag profiles for both the pre- and post-event eras. Strangely, the phase spectra appear to be inverted so at frequencies where there was a lead before the event, there is a lag after but for the same delay. The crisis appears to have switched the directions of money flows, which could reflect a change in policy of the Swedish banks and a repatriation of funds from the various local financial markets (Levy-Yeyati, 2009; Brixiova et al., 2009). Clearly, this is a possible conduit of contagion. The ownership structure of the Baltic States' commercial banks, could also explain the similarity of structural change in the flow of funds across Lithuania and Estonia. However, the shift toward longer periodicies in Latvia is not consistent with this. Perhaps the shift towards longer-term maturities is appropriate were short-term funding is deemed non-functioning or unreliable. Brixiova et al. (2009) find that short-term deposits supported loans in the Baltic States. A re-evaluation of this practice could shift them to longer-dated, or other sources of finance. Nevertheless, there has been a structural change and some evidence of an increase in coherence in all three cases. It is possible that the intensification is based on a net repatriation of funds to banks domiciled in Scandinavia, suggesting the contagion is something not so favourable. 


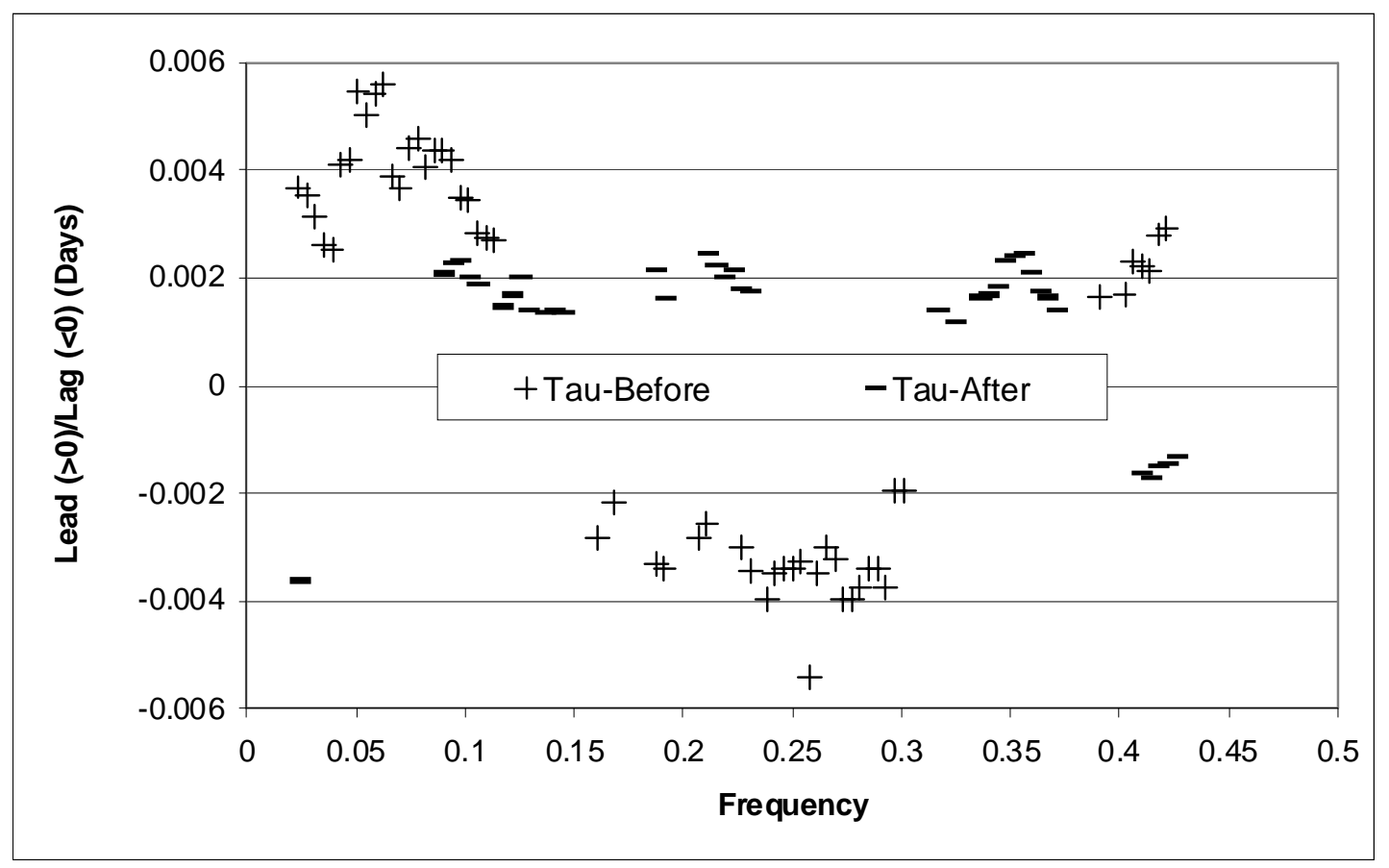

Figure 7. Tau - Euro/Kroon.

$(+)$ indicates that, at frequency $f$, the Euro leads the Kroon by $\tau$ days in the era Before the Event. (-) indicates the corresponding concept but After the Event.

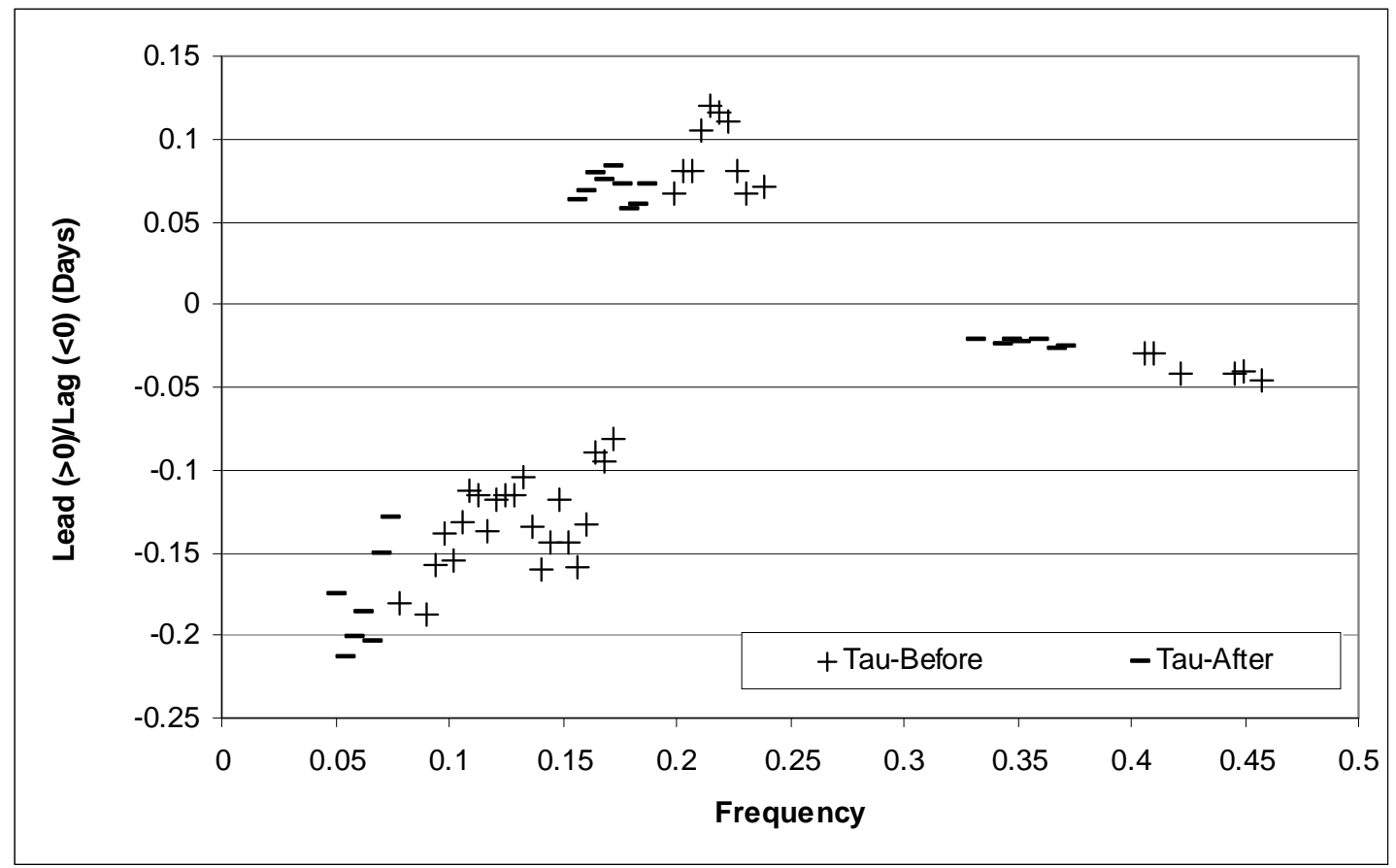

Figure 8. Tau - Euro/Lat

(+) indicates that, at frequency $f$, the Euro leads the Lat by $\tau$ days in the era Before the Event. (-) indicates the corresponding concept but After the Event. 
What contagion represents, in a sense, is a necessary condition for an optimal currency union; that is, an asymmetric shock is dispersed to member countries (De Grauwe, 2003). Once they have acceded, the banking links with other Eurozone countries could be viewed as dimensions of integration. Thus, as portents, these results may be consistent with Yang et al. (2003) and Westermann (2004) in that preparation for EMU precipitates greater market integration. So, for ERMII, favourable foreign currency contagion bodes well for accession and subsequent membership. Against Fischer's (2001) expectation, the Lat, as a softer peg, was not adversely affected relative to the others. However, it could be that an unfavourable repatriation of bank loans from the host to the home country would be, in part, responsible for the intensification of co-movement, so this signal could be open to a different interpretation. Moreover, as the banking links are actually with a nonEurozone member, accession of the Baltic States technically exposes the currency area to a greater likelihood of contagion from turbulence in Sweden, and that this could act asymmetrically within the Eurozone through these three countries. As the period of study ends before the Baltic States begin to contract significantly this could become evident in later data sets.

\section{Conclusions}

As ERMII members, the three Baltic States maintained a fixed exchange rate with the Euro over 2006-8 but that continuity disguises structural change. Rather than causing a divergence between the Euro and the Baltic currencies, coherence indicates that, in a more turbulent period, the event precipitated a closer shadowing of the Euro, which is a sign of success for ERMII countries, supporting De Grauwe and Grimaldi and at odds with Van Poeck et al.. The exchange rate regime does influence coherence. The 
Lat, with its $2 \%$ range around a peg, exhibits lower coherence levels and greater phase values than the Litas or the Kroon. But the less strict regime did not affect the intensification of co-movement.

Phase reveals a difference between the Lat and the other two, with time lags of possibly an hour or so. By contrast, with tighter commitments to the Euro, the Kroon and the Litas exhibit time delays of a matter of minutes. Consistent with tightly managed exchange rates, all three respond within a day. The structure of leads and lags altered for the Lat by maintaining the same delays but at lower frequencies. The other two exhibited a major change in that there is a switch from leading to lagging at major frequency groups. These periodicies are presumed to reflect wholesale money market maturity periods. Moreover, the structural change could be related to the drying-up these of money markets. Given the international ownership structure of the Baltic States' commercial banking sectors, cross-boarder movement of funds could be regimented. The phase spectra inverts suggest the event led to a change in the flow, and possibly a repatriation of funds. Overall, there is evidence of a structural change in co-movements, so shift contagion is found: the event on the $9^{\text {th }}$ August 2007 constitutes a contagion-inducting shock.

Currency co-movement may not be a definitive guide to whether fulfilling EMU convergence criteria prepares a country for Euro accession. The drivers of comovements should be a focus of investigation. If intensification is based on structural bonds, such as trade, then, in a pre-EMU period, they could prove problematic for economic management, but post-accession, they would form some of the necessary building blocks of an optimal currency union. However, if intensification is based on a repatriation of funds to Scandinavian banks, this is less than a favourable shift. In the post-accession era, although one driver, the fear of devaluation, will be expunged, 
the structural link between the Baltic States and Sweden could be the source of asymmetric shocks and constitute a conduit of contagion between the Euro and Krona.

More work should be undertaken to clarify the periodicies in money markets and their link to the spectra discussed. Moreover, there may be other discontinuities that affect the co-movement of currencies not considered. What is featured here concerns only one 'known' one. Spectral analysis as applied here has limitations. The analysis is on a bivariate as opposed to multivariate basis. Jenkins and Watts (1968) show partial coherence and partial phase formulae that can be applied to control for the impact of, say, the Euro. The Euro could mask interactions between the Baltic currencies and others, such as the Swedish Krona. Further work could distil Krona from Euro-based contagious effects.

\section{Acknowledgements}

I am grateful for the useful comments made by an anonymous referee.

\section{References}

Asimakopoulos, I., Goddard, J. \& Siriopoulos, C. (2000) “Interdependence between the US and Major European Equity Markets: Evidence from Spectral Analysis", Applied Financial Economics, Vol. 10.1, pp. 41-47.

Bank of England (2008) Financial Stability Report, No. 24, October www.bankofengland.co.uk.

Brixiova, Z., Vartia, L. \& Worgotter, A. (2009) “Capital Inflows, Household Debt and the Boom-Bust Cycle in Estonia”, William Davison Institute Working Paper No. 965. Conover, C. (1971) Practical Nonparametric Statistics, New York: Wiley. 
Cuaresma, J. \& Hlouskova, J. (2005) "Beating the Random Walk in Central and Eastern Europe", Journal of Forecasting, Vol. 24.3, pp.189-201.

Cuthbertson, K. (1996) Quantitative Financial Economics, New York: Wiley.

De Grauwe, P. \& Grimaldi, M. (2002) "Exchange Rate Regimes and Financial Vulnerability”, European Investment Bank Papers, Vol. 7.2, pp. 33-48.

De Grauwe, P. (2003), The Economics of Monetary Integration, $\left(5^{\text {th }}\right.$ edition), Oxford: OUP.

Fischer, S. (2001) "Exchange rate regimes: Is the bipolar view correct?" The Journal of Economic Perspectives, Vol. 15.2, pp. 3-24.

Harvey, A. (1993) Time Series Models, London: Harvester Wheatsheaf.

Hoesli, M., Lizieri, C. \& MacGregor, B. (1997) "Spatial Dimensions of the Investment Performance of UK Commercial Property”, Urban Studies, Vol. 34.9, pp. $1475-1494$.

Hughes-Hallett, A. \& Richter, C. (2004) "Spectral Analysis as a Tool for Financial Policy: An Analysis of the Short-End of the British Term Structure", Computational Economics, Vol. 23, pp. 271-288.

IMF (2009) Global Financial Stability Report: Navigating the Financial Challenges Ahead October http://www.imf.org/external/pubs/ft/gfsr/2009/02/ Jenkins, G. \& Watts, D. (1968) Spectral Analysis and Its Applications, London: Holden-Day.

Joseph-Khoury, S. \& Wihlborg, C. (2006) "Outsourcing Central Banking: Lessons from Estonia”, Journal of Policy Reform, Vol. 9.2, pp. 125-144.

Kendall, M. \& Ord, K. (1990) Time Series (3 ${ }^{\text {th }}$ edition.), New York: Wiley. Latvijas Banka, (2009) Financial Stability Report. http://wwwbank.lv 
Levy, D. \& Dezhbakhshb, H. (2003) "International Evidence on Output Fluctuation and Shock Persistence", Journal of Monetary Economics, Vol. 50, pp. 1499-1530.

Levy-Yeyati, E. (2009) "Is Latvia the New Argentina?" http://voxeu.org/index.php?q=node/3683 19/10/2009

Maneschiöld, P-O. (2006) "Integration between the Baltic and International Stock Markets", Emerging Markets Finance \& Trade, Vol. 42.6, pp. 25-45,

Pericoli, M. \& Sbracia, M. (2003) “A Primer on Financial Contagion”, Journal of Economic Surveys, Vol. 17.4, pp. 571-608.

Perron, P. (1989) "The Great Crash, the Oil Price Shock, and the Unit Root Hypothesis", Econometrica, Vol. 57, pp.1361-1401.

Serwa, D. \& Bohl, M. (2005) "Financial Contagion Vulnerability and Resistance: A Comparison of European Stock Markets”, Economic Systems, Vol. 29.3, pp. 344-362.

Smith, K. (2001) "Pre- and Post-1987 Crash Frequency Domain Analysis among Pacific Rim Equity Markets", Journal of Multinational Financial Management, Vol. 11.1, pp. 69-87.

Syriopoulos, T. (2007) "Dynamic Linkages between Emerging European and Developed Stock Markets: Has the EMU any Impact?", International Review of Financial Analysis, Vol. 16.1, pp. 41-60.

Van Poeck, A., Vanneste, J. \& Veiner, M. (2007) "Exchange Rate Regimes and Exchange Market Pressure in the New EU Member States", Journal of Common Market Studies, Vol. 45.2, pp. 459-485.

Wang, P. (2003a) “A Frequency Domain Analysis of Common Cycles in Property and Related Sectors", Journal of Real Estate Research, Vol. 25.3, pp. 325-346.

Wang, P. (2003b) Financial Econometrics: Methods and Models, London: Routledge. Westermann, F. (2004) "Does the Euro affect the Dynamic Interactions of Stock 
Markets in Europe? Evidence from France, Germany and Italy", The European Journal of Finance, Vol. 10.2, pp. 139-148.

Yang, J., Min, I. \& Li, Q. (2003) "European Stock Market Integration: Does EMU Matter?", Journal of Business Finance \& Accounting, Vol. 30.9/10, pp. 1253-1276. 


\section{Appendix}

The theoretical spectrum divides up a time series into a set of components that are orthogonal. It reveals the relative power at each frequency corresponding to the variance at each periodicy, so that sharp peaks denote a high concentration. Thus, auto-covariance in the time domain can be represented as a spectrum in the frequency domain. The spectrum is symmetrical in the range $-\pi \leq \omega \leq \pi$, where frequency $\omega$ is measured in radians. The auto-covariance $\gamma_{x}(k)=E\left[\left(x_{t+k}-\mu\right)\left(x_{t}-\mu\right)\right]$ in the time domain is represented as $f_{x}(\omega)=\frac{1}{2 \pi} \sum_{k=-\infty}^{\infty} \gamma_{x}(k) e^{-i k \omega}$ in the frequency domain. This is transformed into $f_{x}(\omega)=\frac{1}{2 \pi}\left[\gamma_{0}+2 \sum_{k=1}^{\infty} \gamma_{x}(k) \cos (\omega k)\right]$. The sample periodogram is estimated as, $\hat{s}_{x}(\omega)=\frac{1}{2 \pi}\left[\hat{\gamma}_{0}+2 \sum_{k=1}^{T-1} \hat{\gamma}_{x}(k) \cos (\omega k)\right]$. The periodogram is not a consistent estimator of the theoretical spectrum: the periodogram is not well behaved as the number of frequencies is a function of $T$ but variance is not. Smoothing is required as the sample is not a consistent estimator of the theoretical spectrum. There is a trade-off between stability and fidelity. The greater the smoothing (a greater $M$, the 'lag window'), the smaller the variance but also the greater the bias and distortion of the theoretical spectrum. The following numbers are used to calculate the confidence intervals: $T=256$ (just below the number of weekdays in a year) and $M=$ 7. The number of degrees of freedom $(v)$ for a Parzen lag window is given as 3.71T/M or 135 . 
The estimated coherence is given by $\hat{C}_{X Y}{ }^{2}\left(\omega_{j}\right)=\frac{\left|\hat{s}_{X Y}\left(\omega_{j}\right)\right|^{2}}{\hat{s}_{X}\left(\omega_{j}\right) \hat{s}_{Y}\left(\omega_{j}\right)}$ where the smoothed sample periodogram, or sample power spectrum of $X$ is $\hat{s}_{X}\left(\omega_{j}\right)$ and $\hat{s}_{X Y}\left(\omega_{j}\right)$ is the sample cross-spectrum.

The Phase value gives a notion of leading (if positive) of the first series $X$ over the second $Y$ at frequency $\omega_{j}$. The estimated phase value $\hat{P}_{X Y}\left(\omega_{j}\right)=\tan ^{-1} \frac{-\hat{q}_{X Y}\left(\omega_{j}\right)}{\hat{c}_{X Y}\left(\omega_{j}\right)}$ where the estimated cospectrum is $\hat{c}_{X Y}\left(\omega_{j}\right)$ and the estimated quadrature spectrum is $\hat{q}_{X Y}\left(\omega_{j}\right)$. The phase value $\hat{P}_{X Y}\left(\omega_{j}\right)$ has a $(\alpha=) 95 \%$ confidence interval of

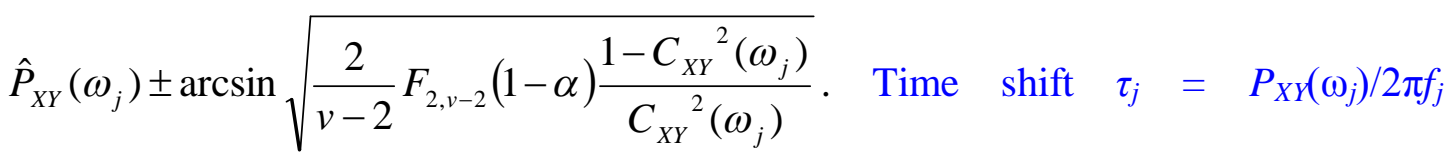
(Harvey, 1993). 